\title{
3D Numerical Analysis of Cracked Ti-TiB FGM Plate with a Semicircular Notch Subjected to Different Modes Load Conditions
}

\author{
Aboubakar Seddik Bouchikhi1*, Nassereddine Bouida' ${ }^{1}$, Farouk Benallal Boukhoulda ${ }^{1}$ \\ ${ }^{1}$ Mechanics of Structures and Solids Laboratory, Department of Mechanics, Faculty of Technology, University of Sidi Bel Abbès, \\ 22000 Sidi Bel Abbes, BP 89, Cité Ben M'hidi, Algeria \\ * Corresponding author, e-mail: asbouchikhi@yahoo.fr
}

Received: 26 September 2018, Accepted: 29 October 2018, Published online: 04 February 2019

\begin{abstract}
This study has been made to determine the performance of the (Ti-TiB) FGM plate to reduce the J-integral calculated for the crack tip emanating from the semicircular notch root in mode I and mixed mode, when the crack is propagated from the notch root. In this paper, 3D finite element method is applied to analyze the behavior of a crack emanating from semicircular notch root growing from the metal (Ti) and is oriented perpendicularly in direction of ceramic (TiB). The J-integral has been found for several combinations laws of FGM plates with respect to the variable combination of the crack length, the plate thickness, the notch radius, Young modulus of FGM plate constituents and the crack orientation. These parameters must be optimized in order to improve the best performances. Keywords
\end{abstract}

FGM, crack, J-integral, fracture mechanic, mode I, mixed mode, finite element methods

\section{Introduction}

It is well-known that traditional layered composite materials and metals possessing high strength and toughness at room and a moderately elevated temperature becomes incapable for employing under the ultra high temperatures. On the other hand ceramic materials demonstrate superior properties in heat resistance. However, the use of ceramics in engineering applications is usually limited due to their low toughness. Combining gradually ceramic and metal materials into one material system, so-called a functionally graded material (FGM), allows one to get advantages of the both materials as an alternative to structures with a bimaterial interface.

The ceramic constituents of FGMs withstand high temperatures due to their excellent thermal resistance, while the metal constituents provide better mechanical performance reducing the possibility of catastrophic brittle fracture. FGMs originally developed as thermal barrier coatings for aerospace structures and fusion reactors [1] have nowadays received a wide spread as structural components in transportation, energy, electronics and biomedical engineering for the general use in high temperature environments [2]. Hence, studies of thermal-induced stresses in FGMs are extremely necessary. Moreover, the existence of microcracks and other defects in FGMs due to features of fabrication processes can essentially affect their material behavior. Therefore, the fracture analyses of FGMs under thermal loading conditions are important to ensure their durability in engineering applications. A number of issues must be addressed in order to effectively model thermal cracking in functionally graded materials. These include profiles of material gradients and their magnitudes, specimen geometry, residual stress distributions, crack-wake and process zone effects for advancing crack, etc. In this respect, various analytical and computational approaches have been employed to investigate crack-tip stress distribution and crack propagation in FGMs [3]. The correspondence between crack-tip fields in homogeneous and non-homogeneous continua, which permits application of standard analysis techniques in FGMs has been demonstrated in $[4,5]$. This fact in conjunction with the simplest approximations of graded material properties allowed researchers to get analytically tractable solutions of many practical tasks reducing them to one dimensional models. For instance, a closedform solution of thermal stress intensity factor (TSIF) for a strip of metal / ceramic FGM with exponentially varying thermo-mechanical properties with an edge crack subjected 
to steady state thermal load was obtained in [6], while the transient thermal problem for such type of graded materials was presented in $[7,8]$ for a cracked semi-infinite plate and a plate with an edge crack, respectively. Authors in [9] have used an analytical approach based on the layered model to study edge cracked strips of ceramic / ceramic and ceramic / metal FGMs with constant elastic moduli and thermal properties graded according to the power law under transient thermal loading conditions. Both the distributions of temperature and thermal-induced stresses in vicinity of the crack have been found.

The J-integral can also be applied to non-homogeneous materials as well as homogeneous materials. Sadowski et al. [10] studied the effect of material non-homogeneity in numerical computations of the J-integral. Sladek et al. [11] employed the J-integral using a domain integral approach to obtain fracture solutions for semi-elliptical surface cracks contained in FGM structures. Use of the J-integral as a fracture parameter in FGMs with notches is the subject of some other papers [12-15].

Although some experimental and numerical investigations of fracture of specimens made of FGMs with cracks are available in the literature, [16-17] there are a few works about fracture assessment of FGMs with notches.

Despite these efforts, a clear description of fracture and crack growth in graded materials has remained a challenging task yet and requires powerful and precise numerical methods. The Finite Element Method (FEM) is undoubtedly a favorite technique for analyzing mechanical and thermal problems including those involving FGMs. The main issue encountered in application of the FEM to FGMs is concerned with modelling a material with continuou varying properties. The simplest way involves the use of homogeneous elements each with different properties, however, it leads to a stepwise change in properties in the direction of the material gradient. Such models have already been used by a number of researchers and reasonable results have been obtained, e.g. [18] among many others. A more advanced way of including property variation into a FE model is to utilize elements that themselves contain a gradient in properties. Authors in [19] proposed a two dimensional (2-D) graded finite element with material properties evaluated directly at the Gauss points. An alternative element was developed in [20], a fully isoparametric element formulation that interpolates material properties at each Gauss point from the nodal values, using the same shape functions as the deformations was proposed. One can notice that comparisons of graded and homogenous elements under various loading conditions with analytical solutions in the literature showed that graded elements give far greater accuracy for modelling FGMs [21].

Moreover, in the case of FGMs, appropriate modifications accounting for material inhomogeneity must be made as compared with the analysis of homogeneous materials for predictions of stresses near the crack-tip and tracking the path of a crack growing in the material, where mode mixity arises not only from geometrical and loading configurations but also from the material nonhomogeneity. It has been proven in [22] that when the traditional version of the J-integral is implemented into the FEM via the domain integration method, it is path dependent in the case of FGMs, and it can provide accurate results only if it is evaluated very close to the crack tip using small elements. A modified path independent J-integral, computed for the nonhomogeneous materials was also proposed in [23] later. However, this quantity is cumbersome to compute. Previous works on crack growth simulation in FGMs includes a number of prediction models. For example, a local remeshing technique to predict the crack path in the quasi-static four-point bending fracture test has been used in [24]. The intrinsic cohesive element formulation in the context of finite element method can be found, e.g. in $[25,26]$. Recently, the novel extended finite element method (XFEM) has been applied to model arbitrary crack growth in FGMs under thermo-mechanical loading in [27, 28].

This paper introduces an elastic-plastic numerical investigation using the 3D finite element method to evaluate the J-integral at crack tip in titanium boride (TiB) titanium (Ti) ceramic-metal functionally graded materials (FGMs) plate with a semicircular notch at side subjected to different mechanical load conditions (mode I and mixedmode). Young's modulus of the functionally graded material plate varies along the specimen width with a power law (P-FGM) and exponential-law (E-FGM) function. Further, the Poisson's ratio is taken as a constant in normal direction to the hole with a power law function. The relation of J-Integral with functionally graded material plate parameters is highlighted; these parameters must be optimized in order to improve the best performances.

\subsection{Geometrical model of the FGM plate}

Fig. 1 illustrates the geometrical model of FGM (Ti-TiB) plate with a side semicircular notch in mode I and mixed mode loading is considered. The geometrical characteristics of the FGM plate are the width $W=200 \mathrm{~mm}$; the 


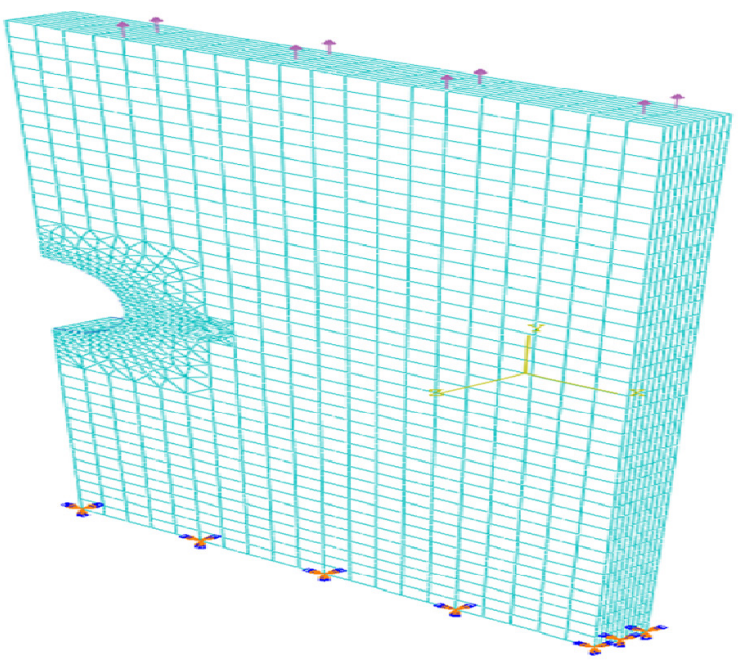

Fig. 1 Geometrical notation of 3D-FGM notched plate

Table 1 Mechanical properties used for metallic of and ceramic phases of FGM material

\begin{tabular}{lc}
\hline Constituents & Young's modulus $(\mathrm{GPa})$ \\
\hline $\mathrm{Ti}$ & 110 \\
$\mathrm{TiB}$ & 375 \\
$\mathrm{Al}$ & 72 \\
$\mathrm{Cu}$ & 124 \\
$\mathrm{Ni}$ & 215 \\
$\mathrm{SiC}$ & 420 \\
$\mathrm{ZrO}_{2}$ & 200 \\
$\mathrm{Al}_{2} \mathrm{O}_{3}$ & 345 \\
\hline
\end{tabular}

length $L=2 W=400 \mathrm{~mm}$; and the thickness $h=2 \mathrm{~mm}$. To analyze the fracture behavior, a crack of length $(c)$ is supposed to be initiated at the notch root with radius $(R)$.

The considered FGM notched plate is requested in different loaded modes:

- Mode (I): $\sigma_{0}=100 \mathrm{MPa}$

- $\operatorname{Mixed} \operatorname{Mode}(\mathrm{I}+\mathrm{II}+\mathrm{III}): \sigma_{0}=\sigma_{1}=\sigma_{2}=100 \mathrm{MPa}$.

Under the effect of the applied stress $\left(\sigma_{0}=100 \mathrm{MPa}\right)$ this crack is susceptible to propagate.

The material properties used for modeling and analysis of FG structures is presented in the Table 1.

\subsection{Finite element model}

The analysis involved a three-dimensional finite element method by using a commercially available finite element code ABAQUS Version 6.9.126 [29].

We used 47538 quadrilateral elements hexahedral and 203416 nodes of type C3D 20R with a refined and

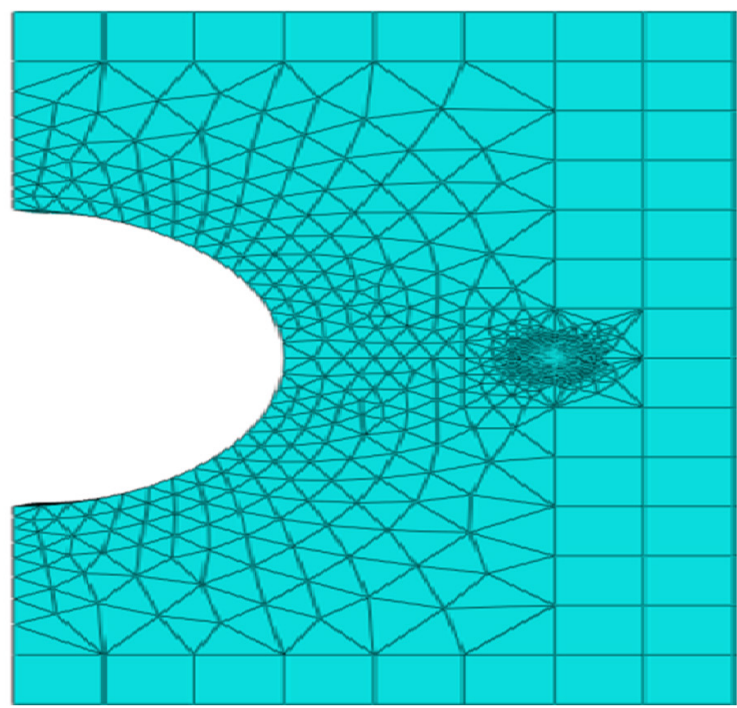

Fig. 2 Typical mesh of 3D-FGM notched plate

structured mesh near the notch as shown in Fig. 2. In the presence of crack, the number of the quadrilateral elements reaches 32213 of type C3D15 and 911 triangular elements of type CPS3. The singularity at the crack head can be integrated in the solution by replacing the elements at the crack head by quarter-point special elements 28 .

The mesh was refined near the crack tip area with an element dimension of $0.066 \mathrm{~mm}$ using at least fifteen such fine elements in the front and back of the crack tip.

\section{Results}

The results are based on the FE analysis, as discussed in the Section 1.2 using Abaqus. Results obtained of different analysis have been presented in the following subsections.

It may be a research interest to compare the J-integral between FGM plate ( $\mathrm{Ti} / \mathrm{TiB}$ ) and homogeneous materials $\mathrm{Ti}$ and TiB plate with respect to the plate depth is shown in Figs. 3 and 4. The mechanical properties of the FGM with a power-law (P-FGM) characterized by material parameter index $(n)$ and exponential-law (E-FGM) function of Young's modulus were considered for three modes of loading (mode I; Mode I + II; Mode I + II + III).

The variation of the FGM properties in the direction of notch radius ( $\mathrm{r}-\mathrm{FGM}$ ) offers the best favorable choice compared to other directions, as it has been mentioned in our previous investigation [30].

In Figs. 3 and 4, it is noticed that the maximum J-integral occur at the thickness of the plate edge and increase gradually as far as middle of the thickness of the plate approaching the asymptotically the value of the applied stress. The curves have a parabolic form. 


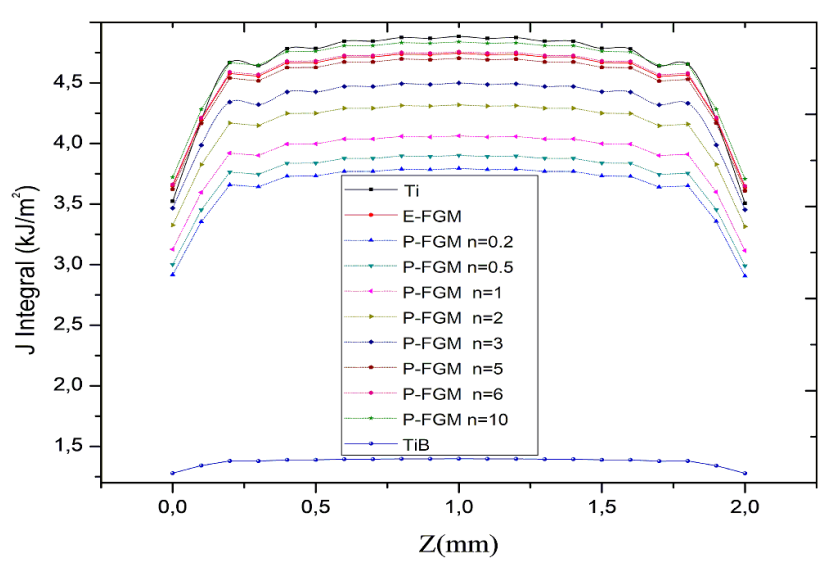

Fig. 3 Variation of the J-integral along the thickness of FGM plate for a normalized crack length. Mode I

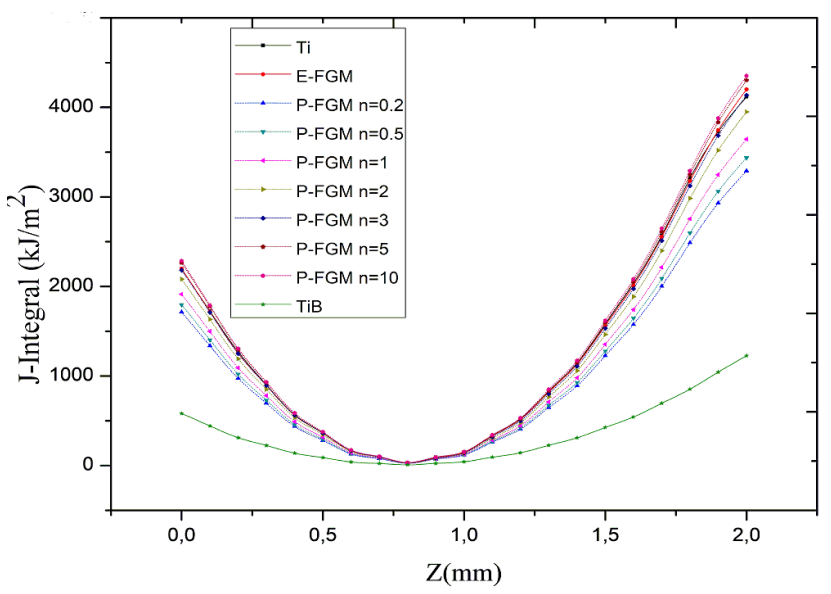

Fig. 4 Variation of the J-integral along the thickness of FGM plate for a normalized crack length. Mode I + II + III

It can be seen also, that the J-integral is more important for metal plates (Ti) than for ceramic plates (TiB). For the P-FGM plate characterized with material parameter index (n), the analysis of the obtained result shows that the increase in this index causes an increasing of the J integral, whereas for $n<6$ we observe that the J-integral value at the P-FGM plate is lower than that found in the E-FGM plate, the value of J Integral for the E-FGM distribution is equal to the value of the J-integral for P-FGM distribution for $n=6$.

It is well known that the formation of cracks is detrimental to mechanical properties of materials and the mechanical loading. Consequently, very low J-integral intensity is required in order to enhance the mechanical properties of FGM plate. To take into account the effect of the kind of mechanical loading on the distribution and amount of J-integral, it is essential to analyze it under different modes load conditions simultaneously, which is a more realistic case.
The variations of the J-integral as a function of three modes loading (mode I), mixed mode (mode I + II + III) are presented in Figs. 3 and 4 respectively.

It is noticed that the J-integral intensities $\mathrm{J}$ (I), and $\mathrm{J}(\mathrm{I}+\mathrm{II}+\mathrm{III})$, in FGM plate in the increase with the increase in the kind of the modes loading from mode I to mode I + II + III. It is noticed also that in the mixed mode the J-integral is more affected that of mode $\mathrm{I}$.

The stiffness of the P-FGM plate (with $n=0.5$ ) is higher than that of the E-FGM plate. While comparing the results, it is noticed that the present work is in good agreement with the work of Claydon [31].

As a result, to continue the analysis of the mechanical behavior of P-FGM plate we limited our study only for power law index $n=0.5$.

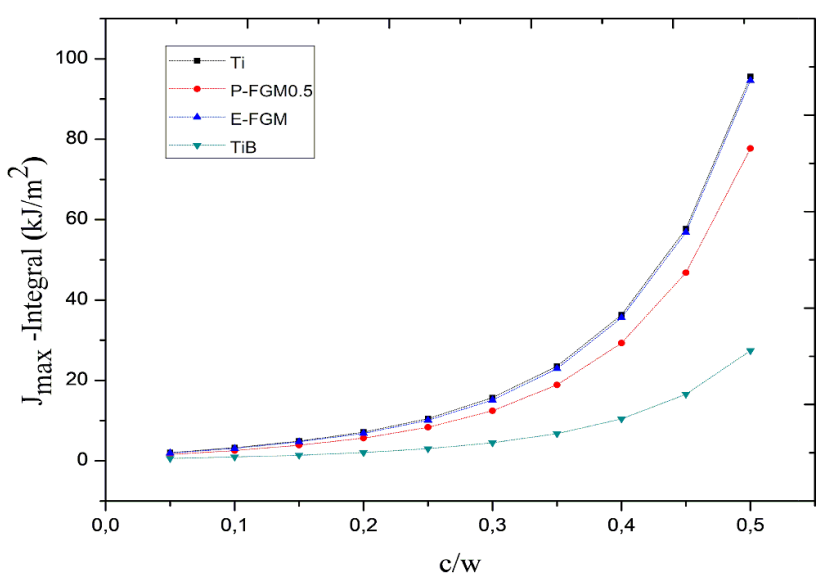

Fig. 5 Variation of the maximal J-integral according to cracknormalized length emanating from the notches. Mode I

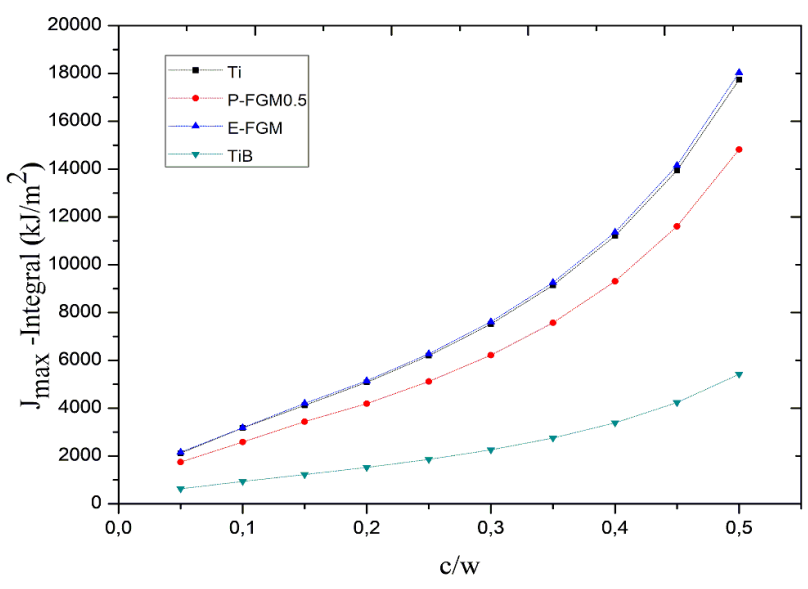

Fig. 6 Variation of the maximal J-integral according to cracknormalized length emanating from the notches. Mode I + II + III 


\subsection{Effect of the crack emanating from the notch on the variation of the $J$-integral}

The crack is found at the notch root and is propagated on the ligament of the plate; in this paragraph, the effect of the crack length on J-integral is analyzed. Figs. 5 and 6 depict the variation of the maximal J-integral at the cracktip according to the crack length from the notch

It is noted that the maximal J-integral increases exponentially with the increasing in crack length and reaches its maximum for the biggest crack length. The difference of J-integral becomes larger and more important with the increase of the crack length. This behavior is normal because the crack propagation leads to an increase of the stress around the crack front, which is the cause of the higher values of the J-integral.

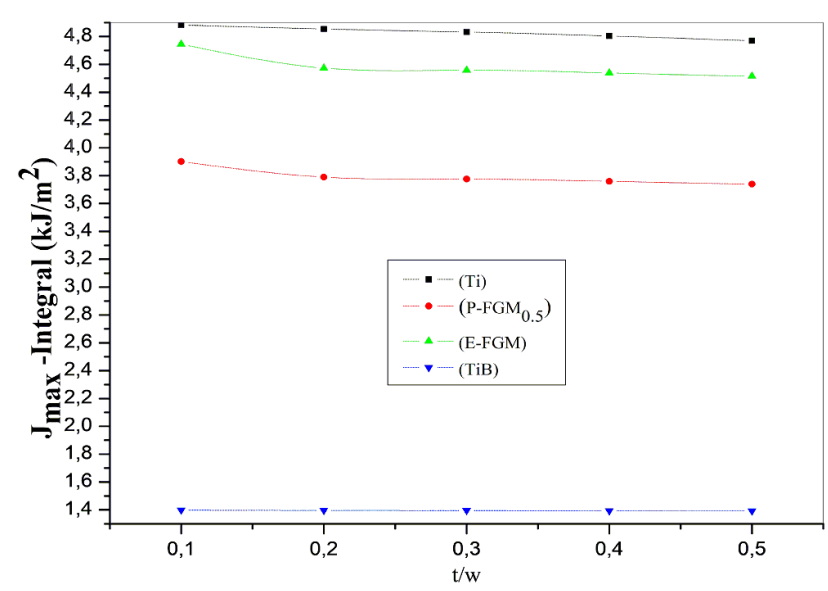

Fig. 7 Variation of the maximal J-integral according to the various normalized thickness. Mode I

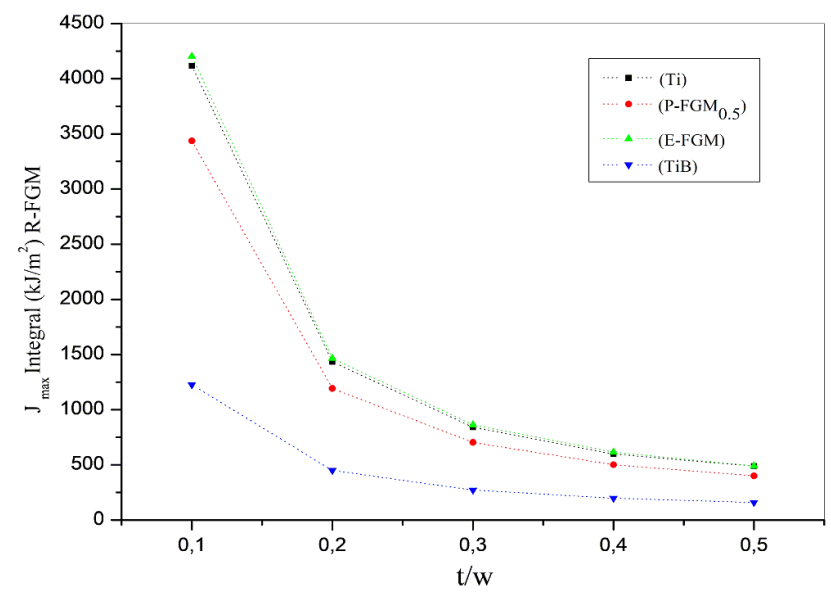

Fig.8 Variation of the maximal J-integral according to the various normalized thickness. Mode I + II + III

\subsection{Effect of the plate thickness on the variation of} the J-integral

To put into evidence the major effect of plate thickness, which is one of the most important parameter in design, a uniform end plate section is considered with different thicknesses. The influence of the thickness of the plates on the extent of the J-integral is analyzed in this section. Figs. 7 and 8 show the effect of the FGM plate's normalized thickness on the variation of the J-integral in the presence of a semicircular notch for two modes of loading.

The figures clearly show(s) that for the mode I loading, the J-integral is quasi-stable when the normalized thickness increases. On the other hand, it is noted that the J-integral at the notch root depends much on the thickness for the mixed mode loading (I + II + III). An increase of the plate thickness leads to a reduction of the J-integral at the notch root in

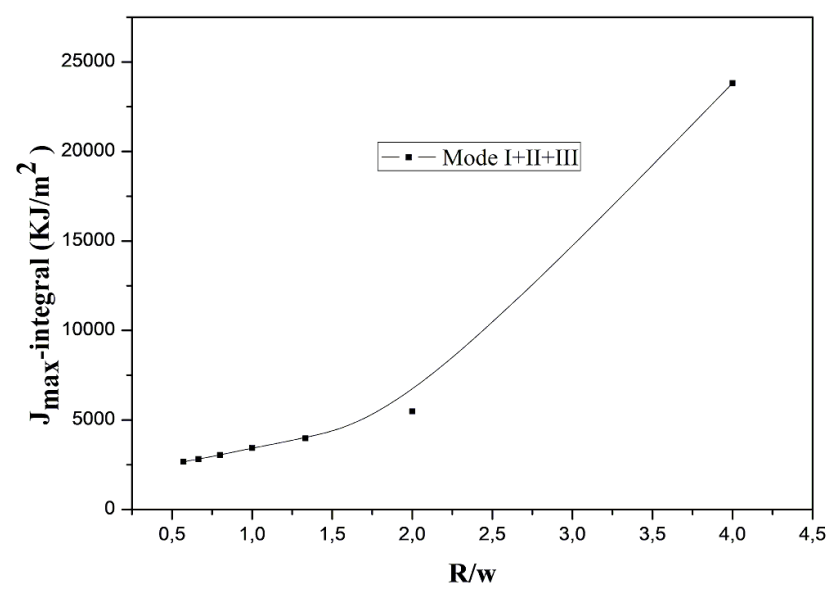

Fig. 9 Variation of the maximal J-integral according to normalized length emanating from notches for versus notch radius for Ti-TiB plate with P-FGM) $n=0.5$. (a) Mode I

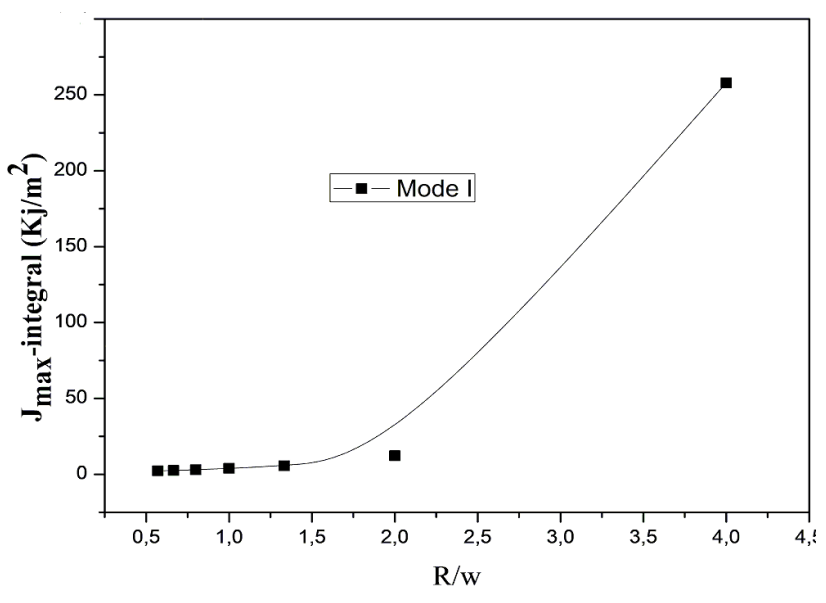

Fig. 10 Variation of the maximal J-integral according to normalized length emanating from notches for versus notch radius for Ti-TiB plate with P-FGM) $n=0.5$. Mode I + II + III 
the FGM plate .This increase is marked much more when the thickness of the FGM plate tends to be a zero value.

\subsection{Effect of the notch root radius on the variation of the J-integral}

The J-integral characterizes the fields of stress and displacement at the crack tip and has an important influence over the velocity of crack propagation. In order to compare the behavior of cracks emanating from semicircular for various notch radii, we study the variation of the J-integral in mode I and mixed mode for various radiuses of notches. However, the crack length is assumed to be constant as $c=10 \mathrm{~mm}$ located in the metal side Ti of FGM plate.

Figs. 9 and 10 present the maximum of the J-integral at the side semicircular notch root in as a function of notch radius under different modes loading for $\mathrm{Ti}-\mathrm{TiB}$ plate with P-FGM $n=0.5$ material distribution function.

We can note that the dimensions of the radius of notches, the increase in the parameter a leads, systematically, to an increase in the J-integral. For the mode I the sensitive is smaller for values smaller than $2(R / c<2)$. On the other hand, when the geometrical ratio $R / c>2$, the J-integral at the crack tip is more important.

We can see also, that the difference in the J-integral between mode I and mixed mode becomes increasingly important with increasing of notch radius.

\subsection{Effect of the Young's modulus of FGM plate constituents on the variation of the J-integral}

To study the influence of the stiffness ratio of FGM plate constituents' materials on the variation of the J-integral with the existence of crack emanating from semicircular notch root. So, the same geometrical model formed by a metal /ceramic couple was considered. The elastic properties of metal and metal are taken as in Table 1.

Elastic modulus of functionally graded plate is assumed to vary continuously throughout the width of the plate, according to the volume fraction of the constituent materials based on the power law with index $n=0.5$.

In the first cases, the crack emanating from the notch is present in (Ti) and is oriented perpendicularly in direction of ceramic. This crack is susceptible to grow under the action of applied load until the ceramic of the metal / TiB couple of FGM plate.

The results are presented in Figs. 11 and 12 present the variation of the J-integral as a function of the crack length emanating from the semicircular notch for various values of the ratio (E1/E2).

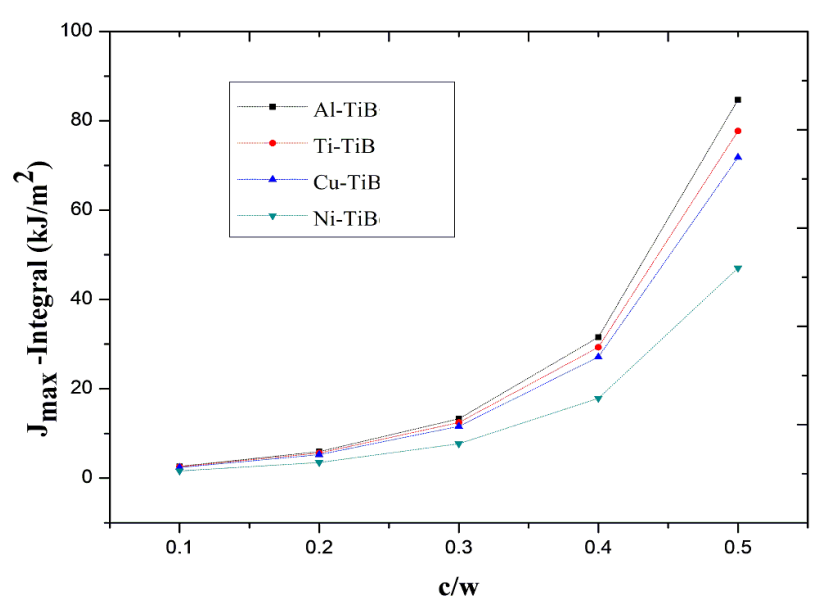

Fig. 11 Variation of the maximal J-integral according to normalized length emanating from notches for various Young's modulus of ceramic. Mode I

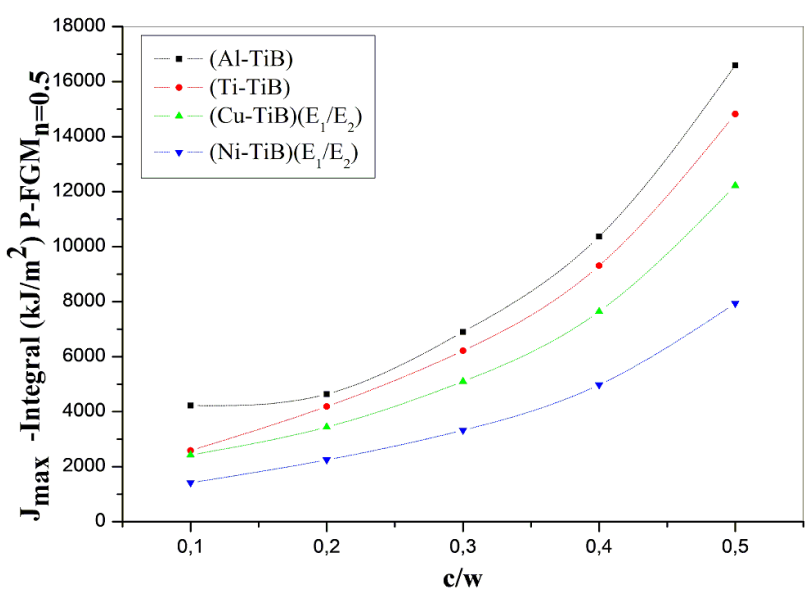

Fig. 12 Variation of the maximal J-integral according to normalized length emanating from notches for various Young's modulus of ceramic. Mode I + II + III

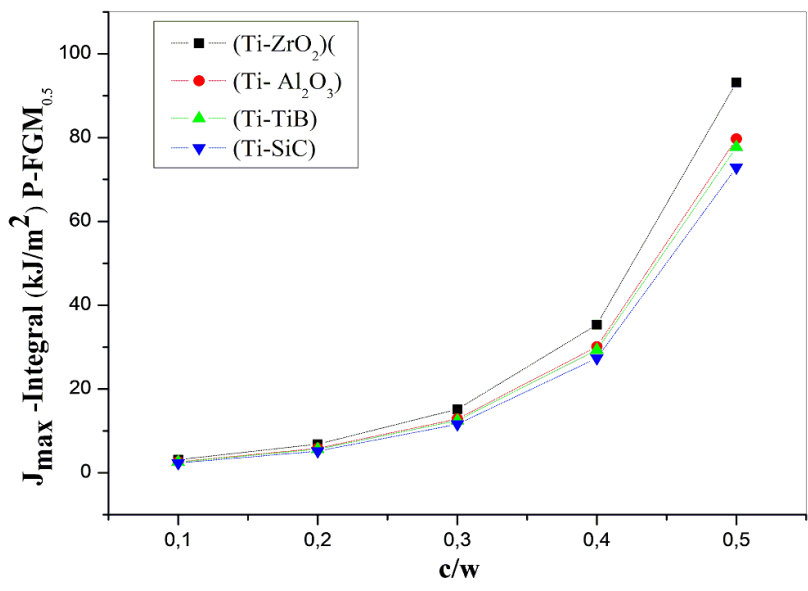

Fig. 13 Variation of the maximal J-integral according to normalized length emanating from notches for various Young's modulus of metal. Mode I 


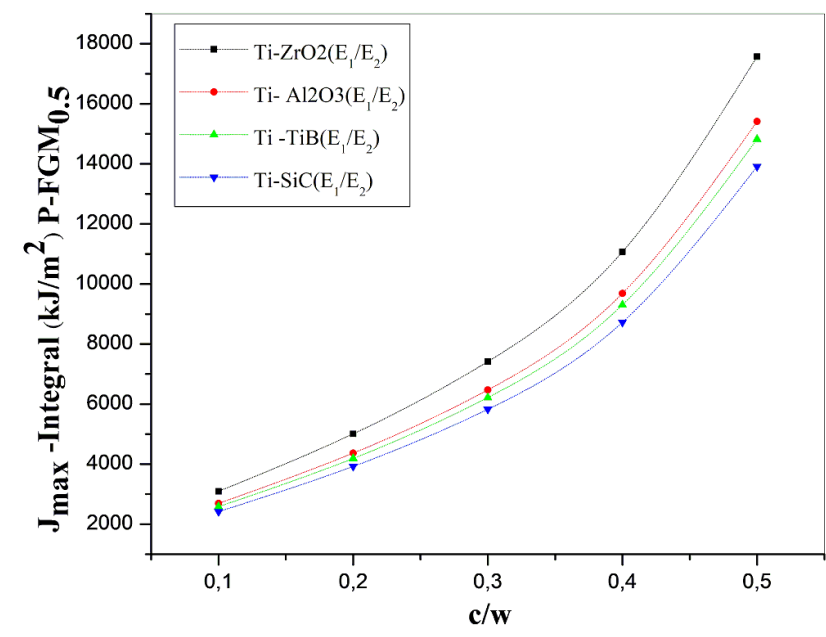

Fig. 14 Variation of the maximal J-integral according to normalized length emanating from notches for various Young's modulus of metal. Mode I + II + III

It can be seen that the values of the J-integral are strongly affected when ratio (E1/E2) is changed so, the J-integral takes a downward curve when the mechanical characteristics of P-FGM) $n=0.5$ plate constituent's materials ratio $(\mathrm{E} 1 / \mathrm{E} 2)$ get stronger. The difference of the J-integral becomes important with the increase in the geometrical size defect characterizing the initiation and propagation of the crack. In other words, the J-integral is decreased with the increase of the Young's modulus of metal at side of FGM plate.

The results of Figs. 13 and 14 confirm the phenomenon observed in Figs. 11 and 12. Indeed, when the crack goes towards a higher strength material, the J-integral decreases in the neighborhood of in the notch for the couple ( $\mathrm{Ti} /$ ceramic). On the other hand, the presence of the crack in a rigid material involves an increase in the J-integral and the crack propagation energy takes importance by growing from the material with higher strength towards the material with lower strength, this increase depends on the elastic properties of the present material.

On one hand, the crack propagation energy takes importance by growing from the material with higher strength towards the material with lower strength. Moreover, this increase is higher with the decrease of the Young's modulus of ceramic.

\subsection{Effect of loading on the variation of the J-integral}

To analyze the effect of the types of mechanical loading applied on the $\mathrm{J}$ integral for different modes of a notched PFGM) $n=0.5$ plate for various sizes of crack, the following cases considered are plotted in Figs. 15 and 16,

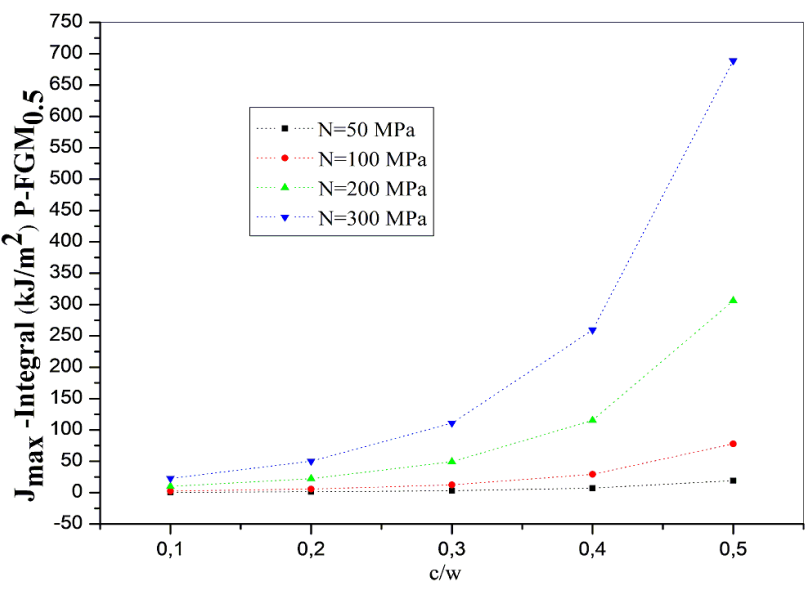

Fig. 15 Variation of the maximal J-integral according to normalized length emanating from notches for various applied loading. Mode I

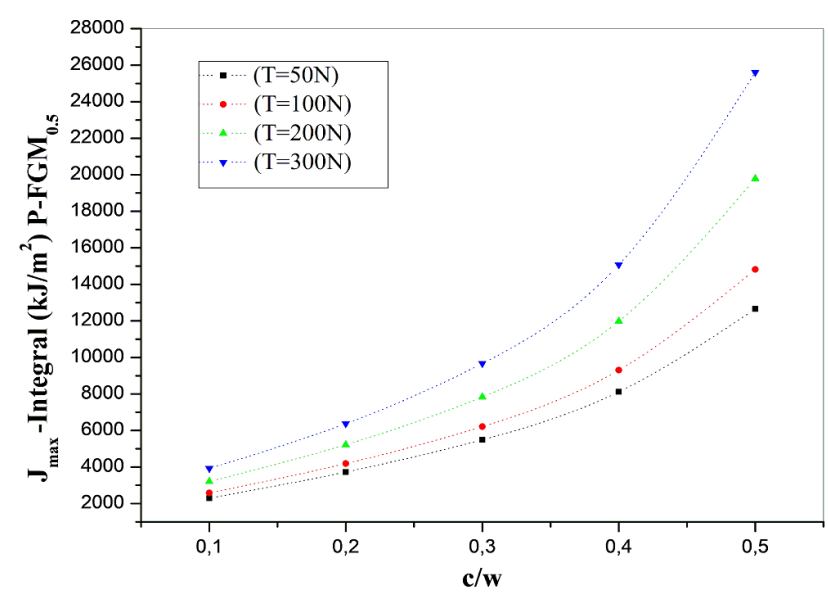

Fig. 16 Variation of the maximal J-integral according to normalized length emanating from notches for various applied loading. Mode I + II + III

we noticed that the $\mathrm{J}$ is affected proportionally with the loads whatever the mode. The increase in the loading leads to the increase in the $\mathrm{J}$ integral.

\section{Conclusion}

The results obtained in this study allow us to deduce the following conclusions:

- The FGM notched plate properties have significant effects on the variation of the J-integral at the notch tip.

- The increase in power law index (n) causes an increasing of the J-integral for PFGM plate.

- Summing up the results, it can be concluded that in the mixed mode the J-integral is more affected that of mode I.

- The increase in the size of the crack led to an appreciable increase in the J-integral in the FGM notched plate. 
- The sensibility of the crack propagation characterized by its J-integral is more important in the plate which has higher mechanical resistance.

- When the plate thickness decreases, the propagation energy absorption of the crack emanating from the notch becomes important under mixed mode. Whereas it do not have significant affects on the variation of the $\mathrm{J}$ integral in mode $\mathrm{I}$.

- The radius notch effect on the J-integral at crack tip of the FGM plate has a very significant impact. The increase of the J-integral becomes more and more important with the importance of the semicircular notch radius of the FGM plate.

- When the crack propagates toward a less rigid material it drags an increase of its J-integral: case of the couples (ceramic / metal).

\section{References}

[1] Koizumi, M., Niino, M. "Overview of FGM Research in Japan", MRS Bulletin, 20(1), pp. 19-21, 1995.

https://doi.org/10.1557/S0883769400048867

[2] Miyamoto, Y., Kaysser, W. A., Rabin, B. H., Kawasaki, A., Ford, R. G. "Functionally Graded Materials: Design, Processing and Applications", 1st ed., Springer, Boston, MA, USA. https://doi.org/10.1007/978-1-4615-5301-4

[3] Sadowski, T. "Non-Symmetric Thermal Shock In Ceramic Matrix Composite (Cmc) Materials", In: de Borst, R., Sadowski, T. (eds.) Lecture Notes on Composite Materials: Current Topics and Achievements, Solid Mechanicsand And Its Applications, 2nd ed., Springer, Dordrecht, The Netherlands, pp. 99-148, 2009. https://doi.org/10.1007/978-1-4020-8772-1_4

[4] Eischen, J. W. "Fracture of nonhomogenous materials", International Journal of Fracture, 34(1), pp. 3-22, 1987. https://doi.org/10.1007/BF00042121

[5] Jin, Z.-H., Noda, N. "Crack-Tip Singular Fields in Nonhomogeneous Materials", Journal of Applied Mechanics, 61(3), pp. 738-740, 1994. https://doi.org/10.1115/1.2901529

[6] Erdogan, F., Wu, B. H. "Crack Problems in FGM Layers Under Thermal Stresses", Journal of Thermal Stresses, 19(3), pp. 237-265, 1996.

https://doi.org/10.1080/01495739608946172

[7] Jin, Z.-H., Noda, N. "Transient thermal stress intensity factors for a crack in a semi-infinite plate of a functionally gradient material", International Journal of Solids and Structures, 31(2), pp. 203-218, 1994.

https://doi.org/10.1016/0020-7683(94)90050-7

[8] Noda, N., Jin, Z.-H. "Thermal stress intensity factors for a crack in a strip of a functionally gradient material", International Journal of Solids and Structures, 30(8), pp. 1039-1056, 1993. https://doi.org/10.1016/0020-7683(93)90002-O

[9] Jin, Z.-H., Paulino, G. H. "Transient thermal stress analysis of an edge crack in a functinally graded material", International Journal of Fracture, 107(1), pp. 73-98, 2001. https://doi.org/10.1023/A:1026583903046
- When the crack is propagated in a ductile material its J-integral at crack tip decreases; whereas the inverse phenomenon occurs if the crack is propagated towards a lower strength material; its J-integral at crack tip increases, it tends to accelerate.

- When the crack is propagated towards a higher strength material, it's J-integral at crack tip decreases.

- The J integral is affected by the effect of the loading according to crack size, when applied load increase the J integral increase and vice versa where the influence of the loading increases with the increase in crack length.

[10] Sadowski, T., Neubrand, A. "Thermal Shock Crack Propagation in Functionally Graded Strip", In: International Symposium on Brittle Matrix Composites (BMC), Warsaw, Poland, 2003, pp. 81-90. https://doi.org/10.1016/B978-1-85573-769-3.50013-7

[11] Sladek, J., Sladek, V., Zhang, C. "An advanced numerical method for computing elastodynamic fracture parameters in functionally graded materials", Computational Materials Science, 32(3-4), pp. 532-543, 2005.

https://doi.org/10.1016/j.commatsci.2004.09.011

[12] Yıldırım, B., Kutlu, Ö., Kadioğlu, S. "Periodic crack problem for a functionally graded half-plane an analytic solution", International Journal of Solids and Structures, 48(21), pp. 3020-3031, 2011. https://doi.org/10.1016/j.ijsolstr.2011.06.019

[13] Petrova, V., Schmauder, S. "Mathematical modelling and thermal stress intensity factors evaluation for an interface crack in the presence of a system of cracks in functionally graded / homogeneous biomaterials", Computational Materials Science, 52(1), pp. 171-177, 2012. https://doi.org/10.1016/j.commatsci.2011.02.028

[14] Petrova, V., Schmauder, S. "Interaction of a system of cracks with an interface crack in functionally graded / homogeneous bimaterials under thermo-mechanical loading", Computational Materials Science, 64, pp. 229-233, 2012.

https://doi.org/10.1016/j.commatsci.2012.04.032

[15] Petrova, V., Sadowski, T. "Theoretical modeling and analysis of thermal fracture of semi-infinite functionally graded materials with edge cracks", Meccanica, 49(11), pp. 2603-2615, 2014. https://oi.org/10.1007/s11012-014-9941-x

[16] Altenbach, H., Eremeyev, V. A. "Mechanics of Viscoelastic Plates Made of FGMs", In: Murín, J., Kompiš, V., Kutiš, V. (eds.) Computational Modelling and Advanced Simulations, Computational Methods in Applied Sciences, 4th ed., Springer, Dordrecht, The Netherlands, pp. 33-48, 2011. https://doi.org/10.1007/978-94-007-0317-9_2 
[17] Bîrsan, M., Altenbach, H., Sadowski, T., Eremeyev, V. A., Pietras, D. "Deformation analysis of functionally graded beams by the direct approach", Composites Part B: Engineering, 43(3), pp. 1315-1328, 2012.

https://doi.org/10.1016/j.compositesb.2011.09.003

[18] Fujimoto, T., Noda, N. "Influence of the Compositional Profile of Functionally Graded Material on the Crack Path under Thermal Shock", Journal of the American Ceramic Society, 84(7), pp. 1480-1486, 2001.

https://doi.org/10.1111/j.1151-2916.2001.tb00864.x

[19] Santare, M. H., Lambros, J. "Use of Graded Finite Elements to Model the Behavior of Nonhomogeneous Materials", Journal of Applied Mechanics, 67(4), pp. 819-822, 2000. https://doi.org/10.1115/1.1328089

[20] Kim, J.-H., Paulino, G. H. "Finite element evaluation of mixed mode stress intensity factors in functionally graded materials", International Journal for Numerical Methods in Engineering, 53(8), pp. 1903-1935, 2002.

https://doi.org/10.1002/nme.364

[21] Buttlar, W. G., Paulino, G. H., Song, S. H. "Application of Graded Finite Elements for Asphalt Pavements", Journal of Engineering Mechanics, 132(3), pp. 240-248, 2006.

https://doi.org/10.1061/(ASCE)0733-9399(2006)132:3(240)

[22] Gu, P., Dao, M., Asaro, R. J. "A Simplified Method for Calculating the Crack-Tip Field of Functionally Graded Materials Using the Domain Integral", Journal of Applied Mechanics, 66(1), pp. 101-108, 1999. https://doi.org/10.1115/1.2789135

[23] Anlas, G., Santare, M. H., Lambros, J. "Numerical Calculation of Stress Intensity Factors in Functionally Graded Materials", International Journal of Fracture, 104(2), pp. 131-143, 2000. https://doi.org/10.1023/A:1007652711735

[24] Tilbrook, M. T., Moon, R. J., Hoffman, M. "Finite element simulations of crack propagation in functionally graded materials under flexural loading", Engineering Fracture Mechanics, 72(16), pp. 2444-2467, 2005.

https://doi.org/10.1016/j.engfracmech.2005.04.001
[25] Jin, Z.-H., Paulino, G. H., Dodds Jr., R. H. "Cohesive fracture modeling of elastic-plastic crack growth in functionally graded materials", Engineering Fracture Mechanics, 70(14), pp. 1885-1912, 2003. https://doi.org/10.1016/S0013-7944(03)00130-9

[26] Rangaraj, S., Kokini, K. "A Study of Thermal Fracture in Functionally Graded Thermal Barrier Coatings Using a Cohesive Zone Model", Journal of Engineering Materials and Technology, 126(1), pp. 103-115, 2004. https://doi.org/10.1115/1.1631028

[27] Comi, C., Mariani, S. "Extended finite element simulation of quasi-brittle fracture in functiinally graded materials", Computer Methods in Applied Mechanics and Engineering, 196(41-44), pp. 4013-4026, 2007. https://doi.org/10.1016/j.cma.2007.02.014

[28] Ivanov, I. V., Sadowski, T., Pietras, D. "Crack propagation in functionally graded strip under thermal shock", The European Physical Journal Special Topics, 222(7), pp. 1587-1595, 2013. https://doi.org/10.1140/epjst/e2013-01947-3

[29] ABAQUS "Finite Element Program, ABAQUS/Standard 6.9.1.", Hibbit, Karlsson and Sorensen, Inc., Pawtuket, USA, 2008.

[30] Gouasmi, S., Megueni, A., Bouchikhi, A. S., Zouggar, K., Sahli, A. "On the Reduction of Stress Concentration Factor Around a Notch Using a Functionally Graded Layer", Materials Research, 18(5), pp. 971-977, 2015. https://doi.org/10.1590/1516-1439.025115

[31] Claydon, P. W. "Maximum energy release rate distribution from a generalized 3D virtual crack extension method", Engineering Fracture Mechanics, 42(6), pp. 961-969, 1992. https://doi.org/10.1016/0013-7944(92)90135-2 